\title{
Acute Malnutrition and Infection with the Human Immuno-Deficiency Virus (HIV) in Children Followed up at the Pediatrics University Hospital Charles de Gaulle: Evolution of Anthropometric Parameters on Antiretroviral Treatment
}

\author{
Aïssata Kaboré*, Sylvie Armelle P. Ouédraogo, Lassina Dao, Fla Koueta, Diarra Yé \\ Service de Pédiatrie Médicale, Centre Hospitalier Universitaire Pédiatrique Charles De Gaulle de Ouagadougou \\ Ouagadougou, Burkina Faso \\ Email: "sita_kab@yahoo.fr
}

Received 18 November 2015; accepted 5 March 2016; published 8 March 2016

Copyright (C) 2016 by authors and Scientific Research Publishing Inc.

This work is licensed under the Creative Commons Attribution International License (CC BY).

http://creativecommons.org/licenses/by/4.0/

(c) (i) Open Access

\section{Abstract}

Burkina Faso, a country with very scarce resources, undertook to fight against HIV infection. In 2013 , according to UNAIDS, 110,000 persons were living in this country with HIV infection. 18,000 children among these persons were under 15 . We conducted a retrospective study from January 2003 to December 2012 at the Pediatrics University Hospital Charles De Gaulle, Ouagadougou (CHUP CDG), Burkina Faso. The study aimed at assessing the children's ponderal growth when under antiretroviral treatment. The children who were under 15 and who had been on antiretroviral treatment for at least 5 years were included in the study. Acute malnutrition concerned children whose height/weight ratio (H/W) was lower at -2 width type (or $\mathrm{Z}$ score) of the median of reference regarding age according to WHO. Two categories of malnutrition were outstanding in our study: moderate acute malnutrition, $(-3 \mathrm{Z}$-score $\leq \mathrm{H} / \mathrm{W}<-2 \mathrm{Z}$-score) and severe acute malnutrition $(\mathrm{W} / \mathrm{H}<-3 \mathrm{Z}$-score $)$. The clinical and paraclinical data recorded during previous consultations were extracted from the ESOPE (Monitoring and follow-up of patients) data basis and exported to the ENA software and SPSS for their analysis. In total, 210 out of 529 children's cases were considered. These children's average age was 6.9 years. There were $55.7 \%$ of male and $44.3 \%$ of female children. HIV1 was found in $97.6 \%$ of the children against $2.4 \%$ for HIV2. In a 5 year follow-up, 46 among the children, namely $20.4 \%$ were on a second line protocol of antiretro-

\footnotetext{
"Corresponding author.

How to cite this paper: Kaboré, A., Ouédraogo, S.A.P., Dao, L., Koueta, F. and Yé, D. (2016) Acute Malnutrition and Infection with the Human Immuno-Deficiency Virus (HIV) in Children Followed up at the Pediatrics University Hospital Charles de Gaulle: Evolution of Anthropometric Parameters on Antiretroviral Treatment. Open Journal of Pediatrics, 6, 34-41. http://dx.doi.org/10.4236/ojped.2016.61007
} 
viral treatment and 164 among them were still on a first line protocol of antiretroviral treatment. When they were admitted at hospital, $38 \%$ of the children showed characteristics of acute malnutrition. $17.8 \%$ of these children presented characteristics of severe form of acute malnutrition. During this 5-year follow-up, the average of the $\mathrm{W} / \mathrm{H}$ index of the children gradually rised from $-1.62 \mathrm{Z}$-score when being admitted to $-0.18 \mathrm{Z}$-score at after a 60 -month antiretroviral treatment. Our study showed an effective ponderal catch-up with an average of the $\mathrm{W} / \mathrm{H}$ index at $\mathbf{- 1 . 0 2 \mathrm { Z } -}$ score after a 12-month antiretroviral treatment. This study completed by the search for nutritious factors is likely to influence the infected children's ponderal growth.

\section{Keywords}

Acute Malnutrition, HIV-Infected Children, Antiretroviral Treatment, Burkina Faso

\section{Introduction}

Sub-Saharan Africa remains one of the most affected regions by the pandemic of HIV infection. In 2016, UNAIDS counted 35 million people infected with HIV in the world. 27.7 million of these people live in SubSaharan Africa.

Burkina Faso, a country with very scarce resources, undertook to fight against HIV infection. In 2013, according to UNAIDS, 110,000 persons were living in this country with HIV infection. 18,000 children among these persons were under 15 [1].

The Pediatrics University Hospital, Charles De Gaulle is one of the three reference hospitals in Ouagadougou, Burkina Faso. The medical team regularly admits in consultation a cohort of 529 HIV-infected children. This management is mainly medical, with a nutritional assistance by the World Food Program.

Despite this treatment, the infected children's growth does not seem to be consistent with WHO's norms [2].

In general, these HIV-infected children show signs of a slowing down of their growth [3] having, at times, a state of severe acute malnutrition at the moment of initiation to the antiretroviral treatment (ART) [4]-[9]. This malnutrition is linked to several factors especially under nourishment, chronic diarrhea [10] [11], chronic inflammation [10] eroding the organism's reserves and opportunistic infections.

Many authors have reported on the improvement of the nutritional state by reconsidering the weight growth after starting an antiretroviral treatment [12]-[15].

If this acute weight deficit is reversible, accompanied by a nutritional and medical treatment, the infected children's growth is still not of much interest to authors in our working context.

The objective of our work was to determine the evolution of the ponderal growth (determined by the weight/ height index) of the children on antiretroviral treatment at the Pediatrics University Hospital, Charles De Gaulle.

\section{Methodology}

This was a retrospective study with a descriptive aim in mind on the cohort of HIV-infected children followed up as outpatients at the Pediatrics University Hospital, Charles De Gaulle from 1 January 2003 to 31 December 2012.

All the children who were under 15 and had been on antiretroviral treatment for at least 5 years were included in the study.

The files which were incomplete as well as deceased children when being followed up were also gradually excluded from the analysis.

While this follow-up was on, each child benefitted from a consultation every month during the first year, and then every three months. The children were weighed and measured at the department of external consultation by the same team of nurses.

The weight/height $(\mathrm{W} / \mathrm{H})$ index considered as the index of measure of acute malnutrition. The following group of people was considered as people suffering from acute malnutrition, all those children whose index of weight/height was inferior to -2 , width type (or Z-score of the median of reference regarding age according to WHO). Two categories of malnutrition were outstanding in our study: moderate acute malnutrition, ( $-3 \mathrm{Z}$-score 
$\leq \mathrm{H} / \mathrm{W}<-2 \mathrm{Z}$-score) and severe acute malnutrition (W/H $<-3 \mathrm{Z}$-score).

The biological evaluations were carried out every three months or every six months for the viral charge.

The clinical and paraclinical data recorded during these consultations were extracted from the ESOPE (Monitoring and follow-up of patients) data basis and exported to the ENA software and SPSS for their analysis. For the latter, the weight/height index was compared to WHO's norms for children of the same age. The analysis was based on the annual distribution of the children according to the weight/height ratio, the variation of this index and on the distribution of the children as regards WHO's standard curve.

\section{Results}

\subsection{General Data}

210 out of the 529 files which were examined and which met the inclusion criteria were considered. The children's average age was 6.90 years with extremes of 7 and 15 years. The sex ratio was 1.25 . The orphans who had lost at least one parent (a motherless or fatherless child) were $37.6 \%$. The children were living in town for $86.6 \%$ of the cases.

HIV1 was found in 204 children namely $94.61 \%$ and HIV2 in 6 children. The mothers who were alive at the moment when their child was being initiated to the antiretroviral treatment were all HIV positive (vertical transmission).

When they were admitted to hospital, there were 128 children out of the 210 who had benefitted from a dosage of TCD4 lymphocytes. In the last six months, 28 children had benefitted from a dosage of viral charge which was over 100,000 copies per cubic millimeter $\left(\mathrm{mm}^{3}\right)$ in 23 among them (namely 82.15\%). The other characteristics of the children are listed on Table 1.

Table 1. Children's general characteristics at admission.

\begin{tabular}{|c|c|c|}
\hline Characteristics & Number & Percentage (\%) \\
\hline \multicolumn{3}{|l|}{ Age (in years) } \\
\hline$<5$ years & 85 & 40.47 \\
\hline 5 - 10 years & 86 & 40.95 \\
\hline$>10$ years & 39 & 18.57 \\
\hline \multicolumn{3}{|l|}{ Sex } \\
\hline Female & 93 & 44.3 \\
\hline Male & 117 & 55.7 \\
\hline \multicolumn{3}{|l|}{ OMS clinical Stage } \\
\hline Stage 1 & 8 & 3.8 \\
\hline Stage 2 & 65 & 31 \\
\hline Stage 3 & 103 & 49 \\
\hline Stage 4 & 34 & 16 \\
\hline Immunological status & 128 & \\
\hline${ }^{*} \mathrm{~L}$ TCD4 < 15\% & 94 & 73.43 \\
\hline LTCD4 15\% - 25\% & 24 & 18.75 \\
\hline LTCD4 > 25\% & 10 & 7.8 \\
\hline \multicolumn{3}{|l|}{ Statural growth } \\
\hline Normal & 120 & 57.14 \\
\hline Moderate delay & 55 & 26.3 \\
\hline Severe delay & 35 & 16.66 \\
\hline \multicolumn{3}{|l|}{ Ponderal growth } \\
\hline Normal & 130 & 61.9 \\
\hline Moderate delay & 55 & 26.19 \\
\hline Severe delay & 25 & 11.9 \\
\hline
\end{tabular}

${ }^{*} \mathrm{~L}$ TCD4 = Lymphocytes TCD4. Acute malnutrition was noticeable in 38\% of the children at the initiation of the antiretroviral treatment. 


\subsection{Therapeutic Protocol at Admission}

In our study, the children who were infected were placed on first line protocol of antiretroviral treatment. The therapeutic diagram was decided by an attending doctor after a pre-therapeutic assessment consisting at least of the dosage of the haemoglobin and lymphocytes TCD4 rate.

In our cohort, the therapeutic diagrams were composed of combinations as follows:

"Zidovudine + Lamivudine + Efavirenz" in 30.2 of the cases; "Stavudine + Lamivudine + Névirapine" in $27.30 \%$ of the cases; "Zidovudine + Lamivudine + Névirapine" in $13.37 \%$ of the cases; "Stavudine + Lamivudine + Névirapine" in $27.23 \%$ of the cases. In addition to the antiretroviral treatment (TARV), the children whose rate of TCD4 lymphocytes was lower than $25 \%$ received co-trimoxazole for the prevention of some opportunistic infections.

In 5 years of follow-up, 46 among the children, namely 20.4\% were on a second line protocol and 164 among them were still on a first line protocol.

A part from the medical management, the children who suffer from acute malnutrition received a nutritional treatment based on a national treatment protocol. After hospitalization, they were followed as ambulatory patients and received an irregular nutritional assistance from the World Food Program essentially composed of cereals, oil, and milk.

\subsection{Evolution of the Weight/Height Index}

\subsubsection{Annual Evolution of the Children's Weight/Height Index on Antiretroviral Treatment}

After a year's follow-up, $18.8 \%$ of the children were still suffering from acute malnutrition. After a 60 -month follow-up, no one child showed any sign of severe acute malnutrition.

The annual distribution of the children according to the weight/height $(\mathrm{W} / \mathrm{H})$ index during the follow-up is illustrated on Figure 1.

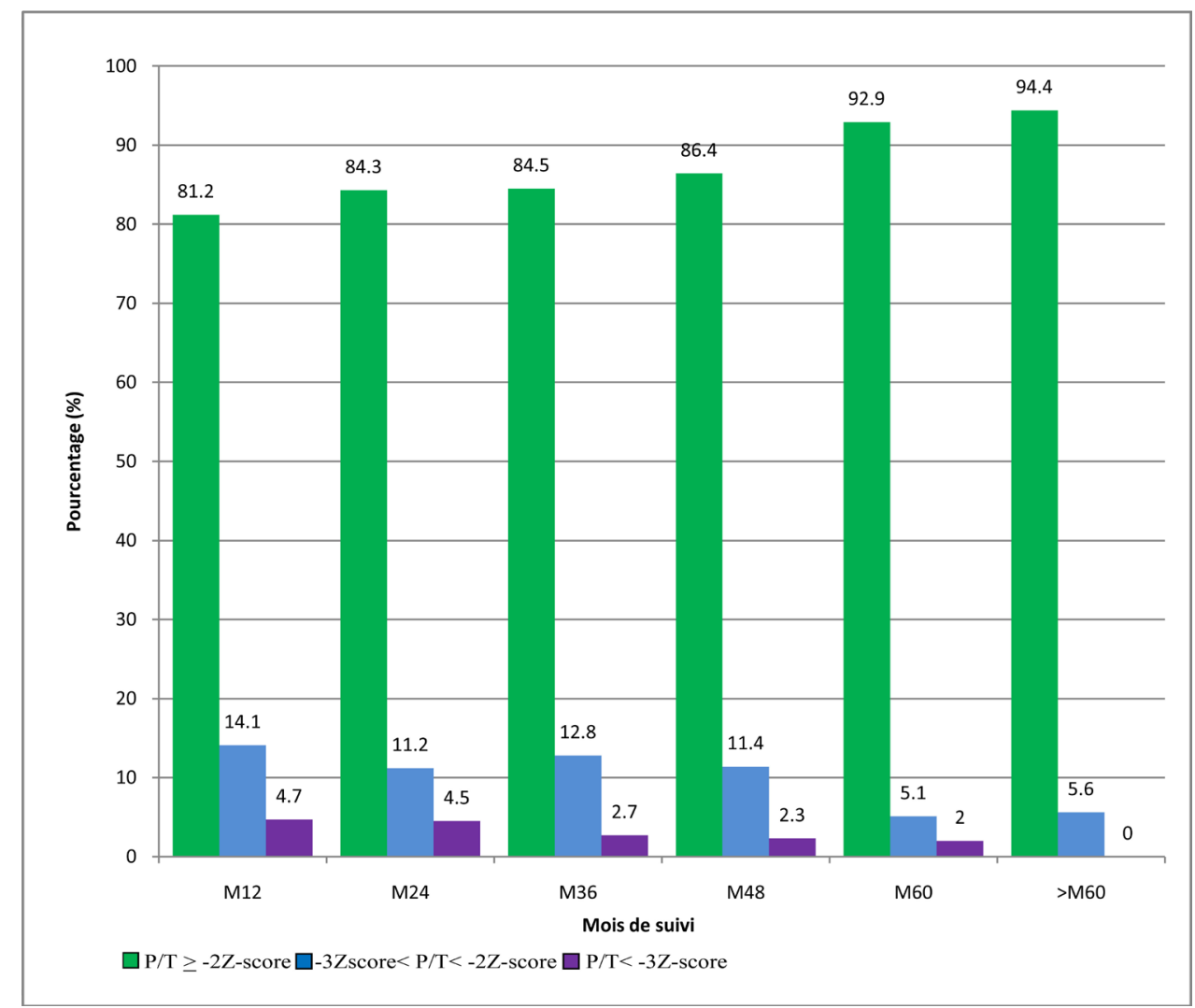

Figure 1. Annual distribution of the children on ARV according to the weight/height (W/H) index. According to the weight/ height index, no one child showed any sign of severe acute malnutrition after a 60-month antiretroviral treatment. 


\subsubsection{Variation of the Average of the Weight/Height Index}

While the follow-up was still on, there was a gradual increase in the average of the weight/height $(\mathrm{W} / \mathrm{H})$ index of the children from -1.62 Z-score when they were admitted to hospital (M0) to -0.18 Z-score after a 60-month follow-up (>M60).

Figure 2 illustrates the variation of the weight/height index during the follow-up.

\subsubsection{Distribution of the Weight/Height Index after 60 Months' Antiretroviral Treatment (M60)}

After a 60 months' follow-up, there were 14 deceased children whose files were excluded from the analysis. The curve of ponderal growth is situated on the left and below the standard curve of WHO having a median at -1 Z-score.

Figure 3 illustrates the distribution of the weight/height index of 196 children after a 60 months' follow-up in relation to WHO's norms.

\section{Discussion}

\subsection{General Data}

The average age of our children was 6.9 years. This age can be compared to the one found by other authors [8] [16]. In Burkina Faso, the starting point of the Prevention of the Transmission Mother to Child of HIV came a little late in 2006. The children who had been followed at the Pediatrics University Hospital Charles De Gaulle since 2002 could not be screened very early and at times were recruited when they were at preschool level still very active.

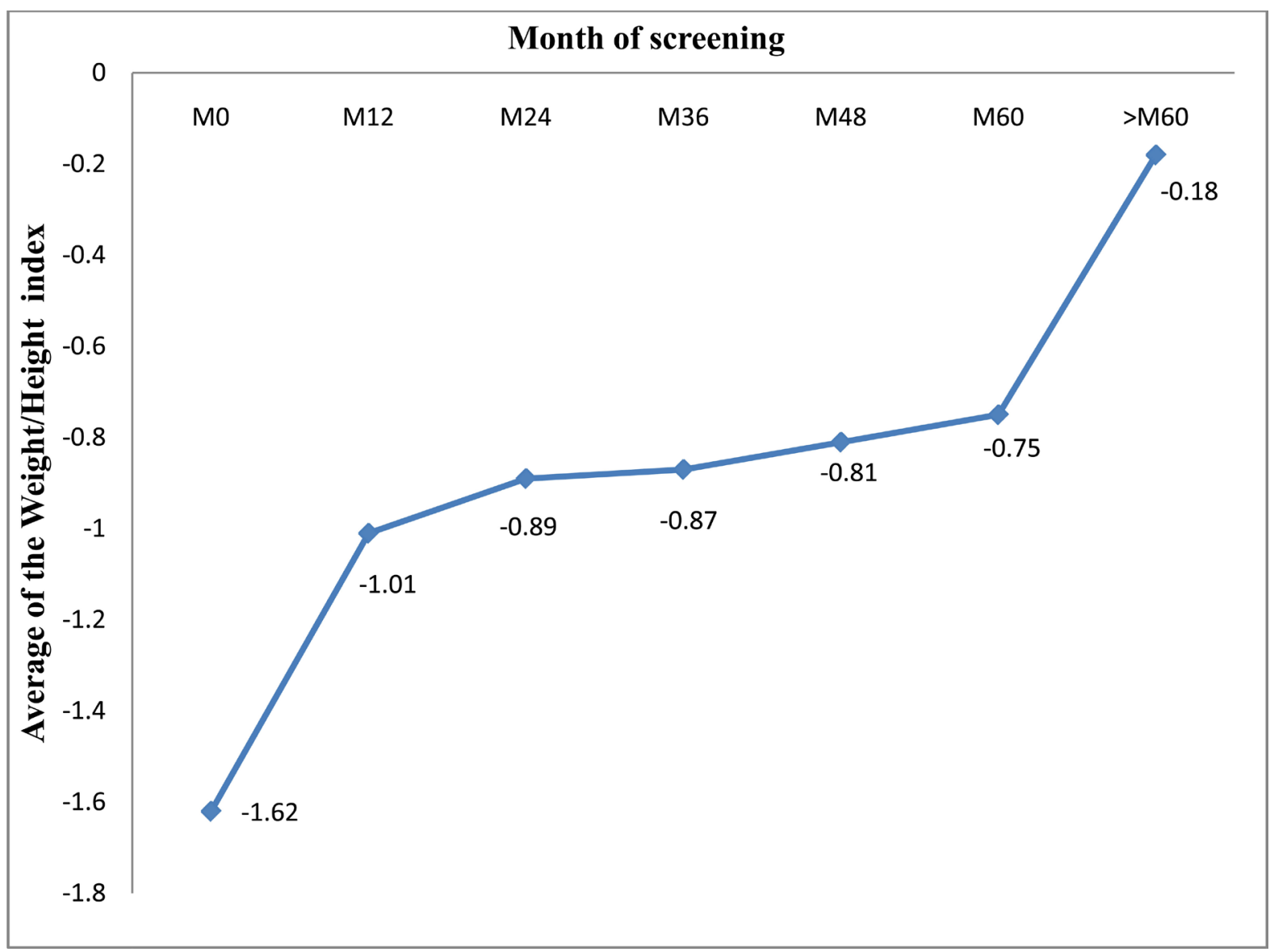

Figure 2. Annual variation of the average of the Weight/Height index. During the follow-up, the average of the W/H index of the children on antiretroviral treatment (ART) has increased gradually ranging from -1.62 at admission (M0) to -0.18 after 60 months' follow-up (>M60). 


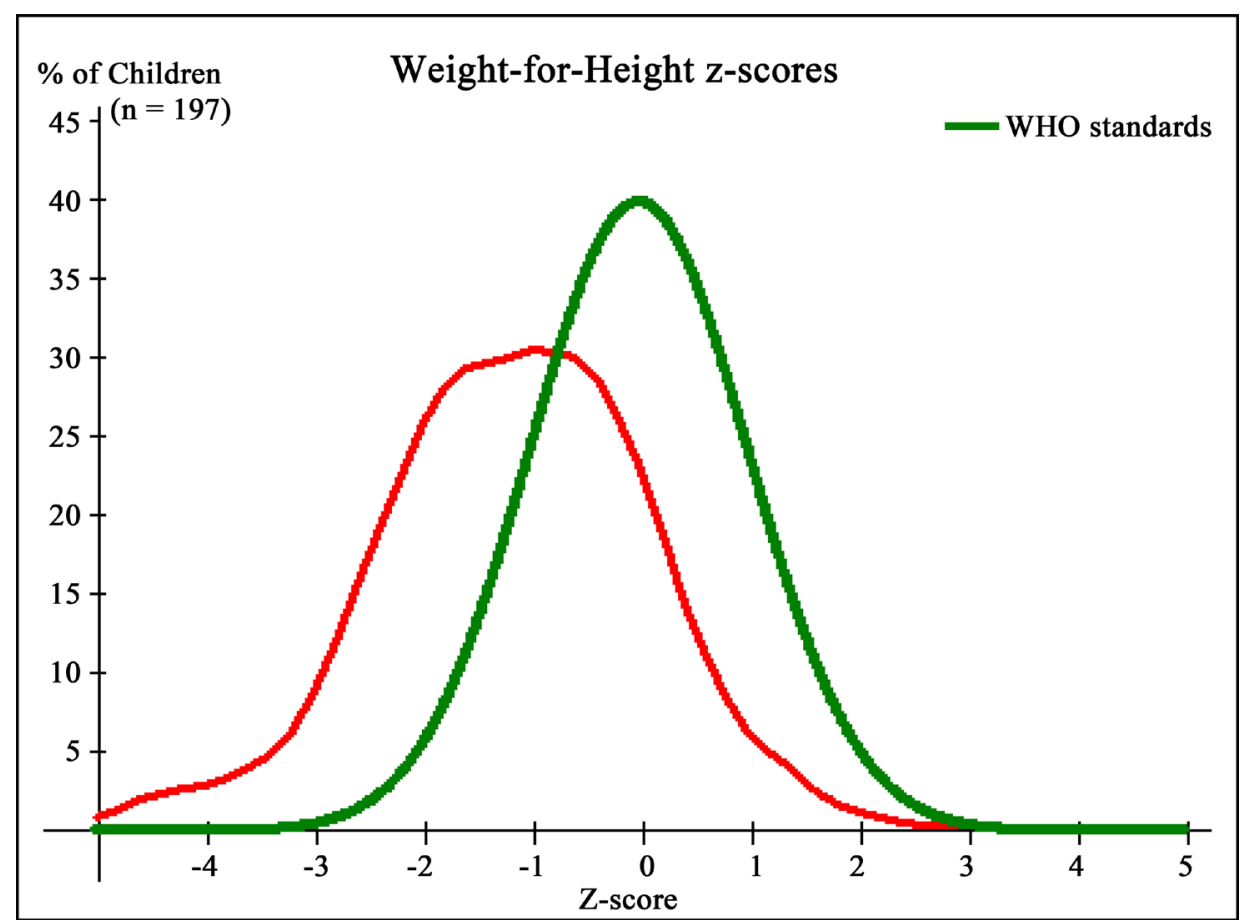

Figure 3. Distribution of the weight/height index of 196 children at M60. After a 60-month follow-up, the curve of the ponderal growth remains on the left and below the standard curve of WHO with a median at -1 .

However, these children's mothers were HIV positive. It is therefore a vertical transmission to HIV which resulted in a gradual erosion of the child's body reserves, a deep depression of his immunity (73.43\%) at the moment when the antiretroviral treatment got started.

As was pointed out by some authors, this state of severe immune-depression tends to favour the sudden arrival of serious opportunistic infections such as tuberculosis [12] and certain impairment in the general state. So, the children who were infected are at times at a severe clinical stage (3 or 4 of WHO classification) when they were being initiated to the antiretroviral treatment [15] [12].

This impairment of the clinical state is, after all, found out as being an important factor of mortality by some authors [10] [17].

\subsection{The Therapeutic Protocol}

The protocol of the antiretroviral treatment (ART) in our study is respectful of the national protocol in Burkina Faso. This diagram took account of the clinical state of the child who is infected. The children whose weight was less than $15 \mathrm{~kg}$ and who were not suffering from anaemia (haemoglobin rate $>10 \mathrm{~g} / \mathrm{dl}$ ) were treated on $\mathrm{Zi}$ dovudine, Lamivudine, and Névirapine; those of them whose weight was over $15 \mathrm{~kg}$ received Efavirenz instead of Névirapine. The children who were anaemic (haemoglobin rate $<10 \mathrm{~g} / \mathrm{dl}$ ) received the same protocol with stavudine instead of Zidovudine (until 2010 when Stavudine was no longer in use according to WHO's recommendation).

These diagrams facilitate a regression of the viral replication. However, the non observance of the antiretroviral treatment by some children might have probably led to a persistent resistance of a positive viral charge. This probably led to starting a second line protocol of antiretroviral treatment in 46 among them with "Abacavir + Videx + Lopinavir/ritonavir”.

\subsection{Evolution of the Weight/Height Index}

Severe acute malnutrition was $38.3 \%$ at admission to hospital in our study. Our results are consistent with those of Centeville et al. who found out 31.5\% of severe acute malnutrition in 127 children infected with HIV [5].

This form of malnutrition is related to a rapid ponderal loss. Indeed, the HIV-infected children are subject to 
anorexia, to digestive troubles especially repeated vomiting, and chronic diarrhea.

These troubles are aggravated by those of digestive absorption of food (by intestinal villous atrophy in some parasitic diarrheas), or opportunistic infections such as tuberculosis [10] [18] [19].

A severe ponderal deficit occurs mainly in children uncontaminated by any antiretroviral treatment. This acute malnutrition is thus mentioned by some authors as being a predictive positive factor in the child's HIV infection [7] [10] [20]-[23]. Others think that severe acute malnutrition might, in return, influence the immune response to the antiretroviral treatment [24].

After the antiretroviral treatment has started, the ponderal growth rapidly evolved. It had a weight/height ratio that ranged from -1.62 Z-score at admission (M0) to $1.01 \mathrm{Z}$-score at the twelfth month (M12).

The catch up of the weight was obtained in our study for $81.2 \%$ of the children in the twelfth month. The same was observed by Nachman who found out in one of his studies on 192 HIV-infected children that the catch up of the children's weight was being done in one year after the antiretroviral treatment has started, and in two years for that of their height [25].

In South Africa, Feinstein found out, after a two years' follow-up of HIV-infected children, a ponderal catch up in $81 \%$ among them against $64 \%$ for the catch up as regards height [12].

Indeed, the antiretroviral treatment would lead to a rapid regression of the viral multiplication and therefore a reduction of the effects that are noxious to the ponderal growth.

The evolution of the average of the weight/height index yet shows stabilization from M12 to M60. That could be attributed to the insufficiency of predominant nutritious provisions in these children; more than a third of them were orphans.

Since the antiretroviral treatment has started, the improvement of the immunity, the regression of the opportunistic infections and that of the digestive troubles might lead to a rapid resumption of the ponderal growth. However, to keep up this growth, it is necessary to go through an adequate nutrition and a strict observance of the antiretroviral treatment in order to avoid taking up the viral replication again.

The number of children who have a positive viral charge during the last six months was 28 in our study. Thus, these children would all continue with an active viral replication which might influence their staturo-ponderal growth.

The rapid ponderal taking up after a M60 follow-up could be linked to the hormonal permeation in the children at their age of puberty. The proportion of these children who were over 10 was $18 \%$ in our study. The release of the anabolic hormones at this age might have an influence on this rapid growth.

\section{Conclusions}

The start of the antiretroviral treatment showed in our study a take up of the growth with a rapid ponderal catchup within a year.

Some studies on the associated factors, above all nutritious factors in the HIV-infected children, might complete our work.

\section{References}

[1] NUSIDA. Programme commun des Nations Unies sur le VIH/sida. Rapport d'activités 2014 sur l'épidémie mondiale du VIH. http://www.unaids.org/fr/countries

[2] OMS. Normes OMS de croissance de l'enfant. Accessible à l'adresse. http://www.who.int/childgrowth/en

[3] Arpadi, S.M. (2000) Growth Failure in Children with HIV Infection. Journal of Acquired Immune Deficiency Syndromes, 25, s37-s42.

[4] Beau, J.P. and Imboua-Coulibaly, L. (1997) Caractéristiques anthropométriques d'enfants malnutris infectés par le VIH en Côte d'Ivoire. Cahiers de santé, 7, 236-238.

[5] Centeville, M., Morcillon, A.M., Filho, A.A.B., et al. (2005) Lack of Association between Nutritional Status and Change in Clinical Category among HIV-Infected Children in Brazil. Sao Paulo Medical Journal, 123, 62-65. http://dx.doi.org/10.1590/S1516-31802005000200006

[6] Diack, A., Signe, S.H., Diagne, G.N.R., et al. (2005) Aspects épidémiologiques et cliniques de l'infection à VIH de l'enfant au centre hospitalier national d'enfants d'Albert-Roye à Dakar. Archives de Pédiatrie, 12, 404-409. http://dx.doi.org/10.1016/j.arcped.2005.01.011

[7] Tall, F., Prazuk, T. and Lafaix, C.H. (1992) Etude de l'infection à VIH chez les enfants malnutris en milieu hospitalier 
pédiatrique (Burkina Faso). Pédiatrie Afrique, 4, 9-15.

[8] Kabue, M.M., Kekitiinwa, A., Maganda, A., et al. (2008) Growth in HIV-Infected Children Receiving Antiretroviral Therapy at a Pediatric Infectious Diseases Clinic in Uganda. AIDS Patient Care and STDS, 22, 245-251. http://dx.doi.org/10.1089/apc.2007.0049

[9] Kariyo, P.C., Mbuzenakamwe, M.J., Baramperanye, E., et al. (2005) Evolution clinique et biologique d'une cohorte d'enfants Burundais sous antirétroviraux (ARV) pendant un an. Médecine d'Afrique Noire, 12, 671.

[10] Chevalier, P.H. (2005) Malnutrition et infection à VIH. Alimentation, Nutrition et Agriculture, No. 34, 5-15.

[11] Ghosn, J. and Bonard, P. (2011) Manisfestations Digestives. In: Girard, P.-M., Katlama, C. and Pialoux, G., Eds., VIH: Edition 2011, Chap. 9, édition Doin, Rueil Malmaison, 145-159.

[12] Feinstein, L., Yotebieng, M., Moultrie, H., Meyers, T. and Van Rie, A. (2012) Effect of Baseline Immune Suppression on Growth Recovery in HIV African Children Receiving Antiretroviral Treatment. Journal of Acquired Immune Deficiency Syndromes, 61, 235-242. http://dx.doi.org/10.1097/QAI.0b013e3182634e09

[13] Hao, J.L., Wang, B.J. and Baptiste, J. (2010) Efficacy of Highly Active Antiretroviral Therapy for Childhood Acquired Immunodeficiency Syndrome. Chinese Journal of Contemporary Pediatrics, 12, 874-876.

[14] Savadogo, L., Zoetaba, I., Donnen, P., Hennart, P., Sondo, B.K. and Dramaix, M. (2007) Prise en charge de la malnutrition aiguë sévère dans un centre de récupération et d’éducation nutritionnelle urbain au Burkina Faso. Revue d'Épidémiologie et de Santé Publique, 55, 265-274. http://dx.doi.org/10.1016/j.respe.2007.05.006

[15] Weigel, R., Phiri, S., Chiputula, F., Gumulira, J., Brinkhof, M., Gsponer, T., Tweya, H., Egger, M. and Keiser, O. (2010) Growth Response to Antiretroviral Treatment in HIV-Infected Children: A Cohort Study from Lilongwe, Malawi. Tropical Medicine \& International Health, 15, 934-944. http://dx.doi.org/10.1111/j.1365-3156.2010.02561.x

[16] Guilléen, S., Ramos, J.T., Resino, R., Bellón, J.M. and Muñoz, M.A. (2007) Impact on Weight and Height with Use of HAART in HIV Infected Children. Pediatric Infectious Disease Journal, 26, 334-338. http://dx.doi.org/10.1097/01.inf.0000257427.19764.ff

[17] Dramaix, M., Hennart, P., Bahwere, P., Mudjene, O., Smets, R., Donnen, P., et al. (1993) Valeur des indicateurs nutritionnels pour le pronostic de la mortalité intra-hospitalière chez les enfants du Kivu. Revue d'Épidémiologie et de Santé Publique, 41, 131-138.

[18] Bobossi, G., Yakoub, S., Nguembi, E., Yassibanda, S., Fikouma, V., Tembeti, P. and Ouilibona, S.F. (2003) Aspects épidémiologiques et cliniques du Sida au complexe pédiatrique de Bangui (Centrafrique). Médecine d'Afrique Noire, 50, 241-245.

[19] Zanoni, B.C., Phungula, T., Zanoni, H.M., France, H., Cook, E.F. and Feeney, M.E. (2012) Predictor of Poor CD4 and Weight Recovery in HIV-Infected Children Initiating ART in South Africa. PLoS ONE, 7, e33611. http://www.plosone.org

[20] Lebela, J. (2009) Croissance staturo-pondérale des enfants infectés par le virus de l’immunodéficience humaine à Yaoundé. Thèse de doctorat, Université de Yaoundé I, Yaoundé, 71 p.

[21] Bulterys, M. and Lepage, P. (1998) Mother-to-Child Transmission of HIV. Current Opinion in Pediatrics, 10, $143-150$. http://dx.doi.org/10.1097/00008480-199804000-00005

[22] Ojukwu, J.U. and Ogbu, C.N. (2007) HIV Infection in Hospitalized Children with Endemic Diseases in Abakaliki, Nigeria: The Role of Climatical Directed Selective Screening in Diagnosis. AIDS Care, 19, 330-336. http://dx.doi.org/10.1080/09540120600822583

[23] Mutombo, T., Keusse, J. and Sangaré, A. (1995) Sida et malnutrition en milieu pédiatrique semi rural ivoirien. Médecine Tropicale, 55, 357-359.

[24] Naidoo, R., Rennert, W., Lung, A., Naidoo, K. and McKerrow, N. (2010) The Influence of Nutritional Status on the Response to HARRT in HIV-Infected Children in South Africa. Pediatric Infectious Disease Journal, 29, 511-513.

[25] Nachman, S.A., Undsey, J.-C., Moye, J., Stanley, K.E., Johnson, G.M., Krogstad, P.A., et al. (2005) Growth of Human Immuno Deficiency Virus Infected Children Receiving Highly Active Antiretroviral Therapy. Pediatric Infectious Disease Journal, 24, 352-357. http://dx.doi.org/10.1097/01.inf.0000157095.75081.43 